\title{
THE HYALURONIC ACID OF SYNOVIAL FLUID IN RHEUMATOID ARTHRITIS
}

\author{
By CHARLES RAGAN AND KARL MEYER \\ (From the Departments of Ophthalmology and Medicine, Columbia University College of \\ Physicians and Surgeons, and the Edward Daniels Faulkner Arthritis Clinic \\ of the Presbyterian Hospital, New York City)
}

(Received for publication July 3, 1948)

Rheumatoid arthritis is considered a disease which involves the connective tissue and supporting structures of the body with its primary nidus in the interfibrillar ground substance of these structures (1). The ground substances are thought to be composed of mucopolysaccharide-protein complexes. The nature of two of the polysaccharides is known-chondroitin sulfuric acid and hyaluronic acid. The latter has been isolated from skin, the vitreous of the eye and from synovial fluid (2). The synovial space has been regarded as an enlarged tissue space (3) and synovial fluid may be obtained with relative ease in many patients with rheumatoid arthritis. A study of the hyaluronic acid in the synovial fluid of patients with rheumatoid arthritis in contrast to normals seemed worthwhile as the characteristics of the hyaluronic acid thus obtained might parallel changes in other mucopolysaccharides in the smaller connective tissue spaces throughout the body.

Hyaluronic acid in synovial fluid is the component of the fluid which is responsible for its high viscosity (4). A variety of quantitative viscosimetric methods have been applied to the viscous nature of synovial fluid since $1925^{\circ}$ (5). These have yielded conflicting data but most seem to agree that normal joint fluid is a very viscous material (6). Bauer, Ropes and Waine (3) demonstrated that there is a wide range of viscosity values obtained from both normal and pathological fluids. We have shown that the viscosity of normal human knee joint fluid varies inversely with the degree of peripheral edema present (7). When joint fluid or purified hyaluronic acid is diluted with 0.85 per cent saline or distilled water an exponential curve is obtained $(8,9)$, and with fluids of high viscosity small increments of diluent fluid cause marked decreases in viscosity. For these reasons, viscosity alone cannot be taken as an index of the concentration of hyaluronic acid or of the extent of polymerization of the mucopoly- saccharide. The concentration of hyaluronic acid may be approximated by the mucinclot method of Bauer et al. (3), but the clot thus formed contains both protein and hyaluronic acid and changes in protein concentration could cause errors in the determination of hyaluronic acid concentration. $\mathrm{Re}$ cently a method has been described whereby the hyaluronic acid content of $1 \mathrm{cc}$. of fluid can be determined with an accuracy sufficient for a biological method (2).

\section{MATERIALS AND METHODS}

Joint fluid was drawn at autopsy from the knees of 11 patients without joint disease. In some of these insufficient fluid was obtained for a 5-cc. viscosimeter. These fluids were diluted with 0.85 per cent saline and the viscosity and turbidimetric determinations of hyaluronic acid were made on the same diluted sample. Fluid was obtained from one or both knee joints of 35 patients with rheumatoid arthritis. Viscosity was determined as described previously (7). Hyaluronic acid concentration was determined by the method of Meyer (2).

The exponential curve derived from dilution of synovial fluid or pure sodium hyaluronate becomes a straight line when the logarithm of the viscosity is plotted against dilution (Figure 1). Dilution mirrors the concentration of hyaluronic acid and thus a straight line relationship exists between the $\log$ viscosity and concentration. A quotient obtained by dividing the $\log$ viscosity by the concentration would be constant for a given fluid regardless of the amount of diluent extracellular fluid introduced. Since the increased viscosity of synovial fluid is due almost completely to the hyaluronic acid present ( 7 , 10) and the viscosity is an index of the polymerization at a given concentration, this quotient gives an approximation of the mean polymerization of the hyaluronic acid present in a sample of fluid. A highly viscous fluid with a low concentration would yield a high quotient and would indicate an highly polymerized hyaluronate. Thus the extent of polymerization would vary directly with the quotient.

\section{RESULTS}

In the normal fluids examined, Table $I$, the quotient was greater than ten in all. Normally 


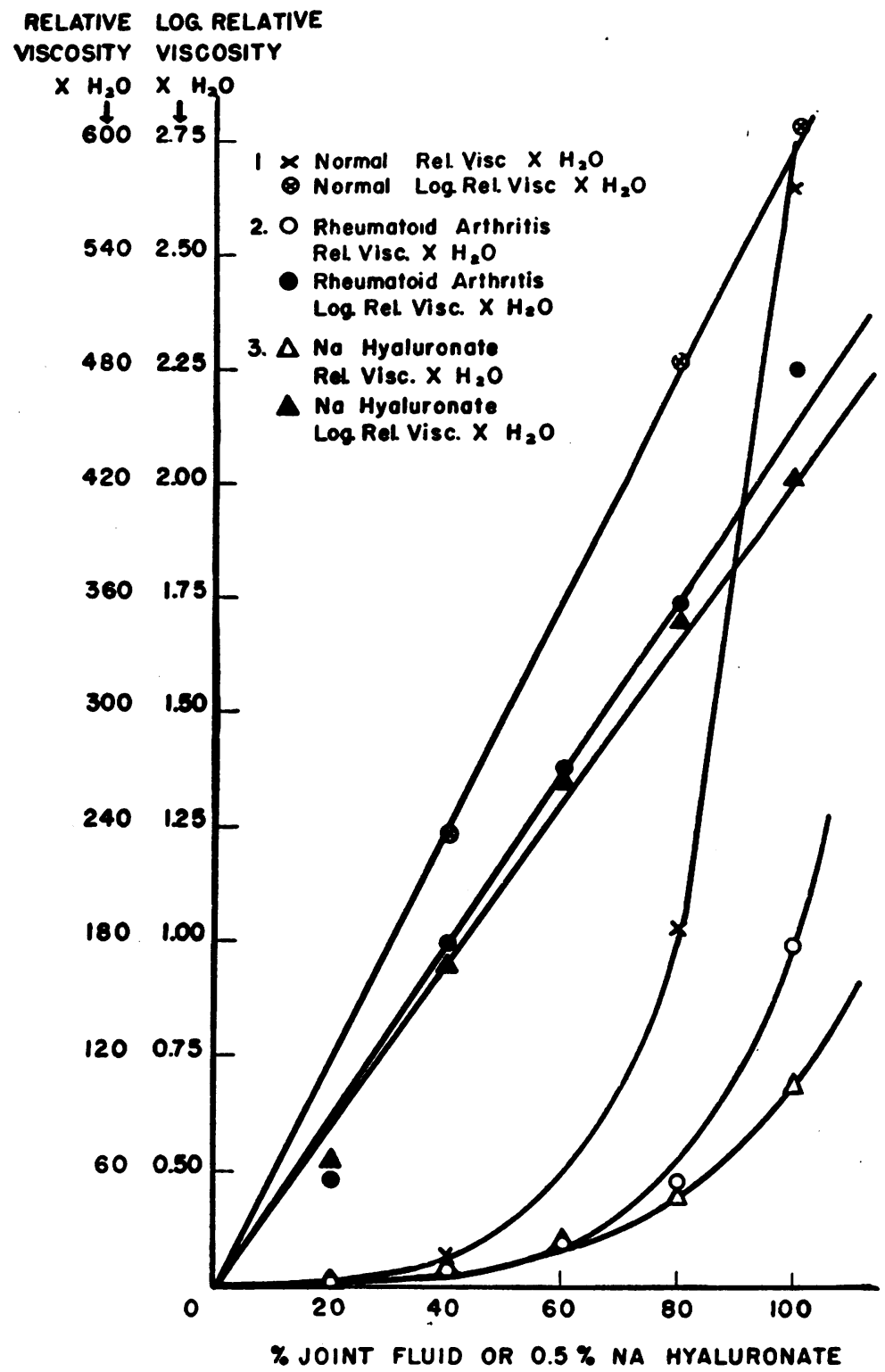

Fig. 1. Dilution Curves Plotted against Relative Viscosity $\times \mathrm{H}_{2} \mathrm{O}$ AND Log RrLative Viscosity $\times \mathrm{H}_{2} \mathrm{O}$

(1) Knee joint fluid obtained at autopsy from a patient without joint disease. (2) Knee joint fluid from a patient with rheumatoid arthritis. (3) 0.5 per cent $\mathrm{Na}$ hyaluronate.

polymerized hyaluronate would have a quotient of ten or above. In the fluid from patients with rheumatoid arthritis (Table II), the quotient was with few exceptions less than ten, which would imply that the hyaluronate in these fluids was less highly polymerized. The severity or intensity of the disease seems to bear some relation to the extent of polymerization of the hyaluronate. With one exception, patient A. Da., all patients in the group with a quotient above 8.10 exhibited few of the criteria of a generalized illness. With the exception of A. Da., these patients could be grouped as smouldering cases or cases in remission. The four patients with quotients above ten were all what is commonly known as "burned-out cases" of long duration with resultant deformity and few 
signs of active disease. On the other hand, patients in the group with a quotient below 8.10 were sick, had many complaints such as fatigability, weight loss, and fever in a few, and exhibited the subjective symptoms which are commonly associated with activity of the rheumatoid process.

The concentration of hyaluronic acid in the patients with rheumatoid arthritis was similar to the concentration in the normal group, but the volume of fluid obtained from the patients with rheumatoid arthritis was far in excess of that removed in the normals. In one patient, $\mathrm{R}$. Re., as much as $300 \mathrm{cc}$. of fluid were removed at regular monthly

TABLE I

Synovial fluid hyaluronic acid in normals

\begin{tabular}{|c|c|c|c|c|}
\hline Patient & - rnee & 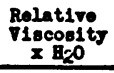 & $\begin{array}{l}\text { Hyaluronice } \\
\text { acid - } \\
\text { nga. } \% \text { ec. }\end{array}$ & 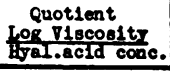 \\
\hline T. Ja. & R1ght & 47.0 & 0.16 . & 10.44 \\
\hline I. Ja. & Loft & 62.2 & 0.17 & 20.54 \\
\hline c. I1. & R1ght & 3.0 & 0.04 & 11.94 \\
\hline A. Po. & Raght & 44.2 & 0.13 & 12.67 \\
\hline A. Fo. & Left & 47.0 & 0.13 & 12.85 \\
\hline A. B. & Right & 5.6 & 0.051 & 14.60 \\
\hline G. Mu. & Both - diluted & 69.8 & $0.336 *$ & 24.74 \\
\hline М.в. & Both & 575.0 & 0.156 & 17.70 \\
\hline H. co. & Both - diluted & 2.3 & $0.10 *$ & 18.10 \\
\hline u. Rq. & Both & 15.1 & 0.06 & 19.63 \\
\hline J. Cu. & Both & 482.0 & 0.135 & 19.89 \\
\hline M. Be. & Both & 365.0 & 0.129 & 19.90 \\
\hline J. Sc. & $\begin{array}{c}\text { Both - diluted } \\
\text { to } 30 \%\end{array}$ & 12.1 & $0.173 *$ & 20.85 \\
\hline
\end{tabular}

* Factor was determined from dilution indicated in the Table.

intervals from the right knee joint and it is not uncommon to remove amounts of 50 to $70 \mathrm{cc}$. at frequent intervals from patients with rheumatoid arthritis. On the other hand, it is rare to obtain as much as $5 \mathrm{cc}$. of fluid from a normal knee joint and 2 cc. is the usual amount which it is possible to withdraw. Therefore, the total amount of hyaluronate found in patients with rheumatoid arthritis is far in excess of that found in normal knees. Our results may be summarized as demonstrating an increased amount of hyaluronate with a low degree of polymerization in patients with rheumatoid arthritis, the extent of polymerization varying inversely with increasing activity of the disease.
TABLE II

Synovial fluid hyaluronic acid in patients with rheumatoid arthritis

\begin{tabular}{|c|c|c|c|c|}
\hline Patlent & Inee & $\begin{array}{r}\text { Relative } \\
\text { V1scosity } \\
\times \mathrm{B}_{20} \\
\end{array}$ & $\begin{array}{c}\text { Byaluron10 } \\
\text { actd - } \\
\text { apeo. }\end{array}$ & $\begin{array}{c}\text { Quotient } \\
\text { Log V1scosity } \\
\text { Ejaluronic acid } \\
\text { concentretion }\end{array}$ \\
\hline 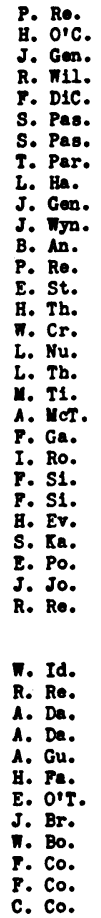 & 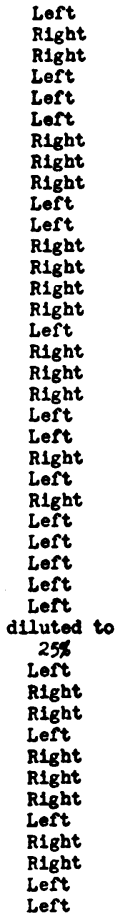 & $\begin{array}{r}5.4 \\
6.5 \\
6.1 \\
13.5 \\
35.0 \\
6.5 \\
4.5 \\
15.7 \\
21.5 \\
8.1 \\
5.2 \\
8.7 \\
7.1 \\
16.2 \\
48.2 \\
12.8 \\
14.2 \\
14.7 \\
21.3 \\
34.8 \\
21.3 \\
29.8 \\
14.2 \\
32.1 \\
5.3 \\
35.8 \\
123.0 \\
15.6 \\
21100.0 \\
19.4 \\
29.4 \\
24.8 \\
38.0 \\
7.6 \\
7.8 \\
55.0 \\
24.2 \\
95.0 \\
21.3 \\
8.5 \\
28.0 \\
23.7 \\
17.0\end{array}$ & $\begin{array}{l}0.177 \\
0.162 \\
0.155 \\
0.228 \\
0.287 \\
0.154 \\
0.120 \\
0.22 \\
0.189 \\
0.160 \\
0.118 \\
0.152 \\
0.134 \\
0.190 \\
0.240 \\
0.155 \\
0.160 \\
0.159 \\
0.180 \\
0.205 \\
0.171 \\
0.190 \\
0.148 \\
0.189 \\
0.09 \\
0.193 \\
0.258 \\
0.147 \\
0.630 \\
0.157 \\
0.137 \\
0.180 \\
0.10 \\
0.10 \\
0.194 \\
0.150 \\
0.203 \\
0.130 \\
0.08 \\
0.120 \\
0.10 \\
0.09\end{array}$ & $\begin{array}{l}4.16 \\
5.02 \\
5.06 \\
5.22 \\
5.39 \\
5.42 \\
5.44 \\
5.44 \\
5.61 \\
5.68 \\
6.08 \\
6.20 \\
6.32 \\
6.43 \\
7.00 \\
7.15 \\
7.22 \\
7.34 \\
7.48 \\
7.52 \\
7.76 \\
7.79 \\
7.79 \\
7.99 \\
8.05 \\
8.06 \\
8.10 \\
8.12 \\
\\
8.20 \\
8.56 \\
8.80 \\
8.90 \\
8.90 \\
9.00 \\
9.22 \\
9.75 \\
10.30 \\
11.60 \\
12.0 \\
13.75 \\
13.90 \\
\end{array}$ \\
\hline
\end{tabular}

The findings presented suggest one of two possibilities: (1) that the hyaluronate has been depolymerized-an active breakdown, and (2) that the hyaluronate has been incompletely polymerized due to a failure in synthesis in active rheumatoid arthritis. We have never been able to detect hyaluronidase in joint fluid and Ropes (9) has been unable to demonstrate the enzyme in synovial tissue or in periarticular tissue. If this low degree of polymerization is due to enzymatic action with depolymerization, the hydrolysis stops at an early stage, since the hyaluronate continues to exist in the fluid in a relatively highly polymerized form. The fiber formation which occurs in normal joint fluid on acidification and addition of normal horse serum (11) is also found to a slight degree in a few fluids from patients with rheumatoid arthritis. In these the polymerization quotient is usually high and the fiber formation may be regarded as an indi- 
cation of the presence of highly polymerized hyaluronate in the fluid. The disappearance of fibers and appearance of colloidal turbidity upon exposure to minute amounts of hyaluronidase means simply that the hyaluronate is less highly polymerized. This does not explain satisfactorily the cause of the relatively low polymerization of the hyaluronate in rheumatoid arthritis since hyaluronate depolymerized in the process of purification by methods completely free of enzymatic hydrolysis also gives a colloidal turbidity. We have no definite evidence as to cause of this decrease in polymerization, but in vivo conditions usually are sufficiently mild to preclude physical depolymerization.

The increased total amount of hyaluronate found in rheumatoid arthritis cannot be explained by the action of hyaluronidase and presupposes that the primary defect lies in the synthesis of this polysaccharide rather than in its enzymatic hydrolysis or non-specific depolymerization. An increased production of incompletely polymerized hyaluronate in rheumatiod arthritis would explain our findings adequately. The site of formation of hyaluronic acid is not known but there is presumptive evidence (2) that the precursor, a disaccharide, is formed in the liver and that the high polymer form is elaborated in the connective tissue. The data presented here would suggest that in rheumatoid arthritis, the primary fault is in the connective tissue cells which are unable to conclude the synthesis of high polymer mucopolysaccharide when presented with oligosaccharides by the liver. An increased formation of incompletely polymerized hyaluronate would be in accord with the histologic changes in this disease in which over growth of connective tissue cells in the form of granulation tissue is the characteristic microscopic finding. This is, furthermore, in keeping with the present concept based on morphopathological as well as clinical grounds that rheumatoid arthritis lies in the realm of the mesenchymal or connective tissue diseases (11).

\section{CONCLUSION}

1. The extent of polymerization of joint fluid hyaluronic acid may be estimated by a quotient derived from the $\log$ of the viscosity divided by the hyaluronic acid concentration.
2. In the joint fluid from patients without joint disease, this quotient was found to be above ten.

3. In joint fluid from patients with rheumatoid arthritis, the quotient was below ten with few exceptions, indicating the presence of incompletely polymerized hyaluronate.

4. The extent of failure of complete polymerization varied with the activity of the disease process. When the disease was more active, the degree of polymerization was less.

5. In rheumatoid arthritis there is an increased production of low-polymer hyaluronate.

6. The bulk of the evidence suggests that the defect in rheumatoid arthritis lies in the normal process of polymerization rather than the excessive breakdown of hyaluronic acid.

\section{ACKNOWLEDGMENTS}

The authors are indebted to Mrs. Audrey Fixell, Miss Hannah Weinshelbaum and Miss Toby Bernstein for their technical assistance.

\section{BIBLIOGRAPHY}

1. Meyer, K., and Ragan, C., Hyaluronic acid and the rheumatic diseases. Modern Concepts of Cardiovascular Disease, 1948, 17, No. 2.

2. Meyer, K., The biological significance of hyaluronic acid and hyaluronidase. Physiol. Rev., 1947, 27, 335.

3. Bauer, W., Ropes, M. W., and Waine, H., The physiology of articular structures. Physiol. Rev., 1940, $20,272$.

4. Meyer, K., Smyth, E. M., and Dawson, M. H., The isolation of a mucopolysaccharide from synovial fluid. J. Biol. Chem., 1939, 128, 319.

5. Schneider, J., Untersuchungen über die Viskosität menschlicher Synovia. Biochem. Ztschr., 1925, $160,325$.

6. Kling, D. H., The nature and origin of synovial fluid. Arch. Surg., 1931, 23, 543.

7. Ragan, C., Viscosity of normal human synovial fluid. Proc. Soc. Exper. Biol. \& Med., 1946, 63, 572.

8. Meyer, K., and Chaffee, E., Hyaluronic acid in the pleural fluid associated with a malignant tumor involving the pleura and peritoneum. J. Biol. Chem., 1940, 133, 83.

9. Ropes, M. W., Discussion on symposium on collagen. Ann. of Rheum. Dis., 1948, 7, 35.

10. Meyer, K., Chaffee, E., Hobby, G. L., and Dawson, M. H., Hyaluronidases of bacterial and animal origin. J. Exper. Med., 1941, 73, 309.

11. Combined Staff Clinics, Rheumatoid arthritis. Am. J. Med., 1946, 1, 675. 